\title{
Evaluation oF Epicardial Fat and Carotid Intima-Media Thickness in Obese Children
}

\author{
Hatem Hamed Elshorbagy,," ElSaeed R. Fouda, ${ }^{1,}$ Naglaa M. Kamal, ${ }^{2}$ Mohammed M. \\ Bassiouny, and Waleed M. Fathi ${ }^{4}$ \\ ${ }^{1}$ Departments of Pediatric, Menofia University, Menofia, Egypt \\ ${ }^{2}$ Departments of Pediatric, Cairo University, Cairo, Egypt \\ ${ }^{3}$ Departments of Pediatric, Tanta University, Tanta, Egypt \\ ${ }^{4}$ Clinical Pathology Department, Menofia University, Menofia, Egypt \\ *Corresponding author: Hatem Hamed Elshorbagy, Departments of Pediatric, Menofia University, Menofia, Egypt. Tel: +96-6567500908, E-mail: shorbagy732000@yahoo.com
}

Received 2014 December 5; Revised 2015 May 1; Accepted 2015 June 14.

\begin{abstract}
Background: Epicardial fat has a role in cardiovascular diseases.

Objectives: To assess epicardial fat and its relation with carotid intima-media thickness (IMT) in obese adolescents with metabolic syndrome(MetS).

Patients and Methods: The study included 60 obese adolescents and 25 control subjects. According to the presence or absence of MetS, obese subjects were divided into two subgroups. We measured weight, height, calculated Body Mass Index, waist circumference, hip circumference, systolic blood pressure, diastolic blood pressure and biochemical parameters (fasting glucose, total cholesterol, triglycerides, high density lipoprotein cholesterol, and low density lipoprotein cholesterol, High sensitivity C-reactive protein, fasting insulin, a homeostasis model assessment index of insulin resistance. plus an echocardiographic examination with measurement of epicardial adipose tissue thickness (EATT).

Results: Left ventricular mass index measurements were significantly higher in MetS group than both non-MS and control groups. The MetS and non-MetS obese patients had significantly higher carotid IMT in comparison to the control group. Carotid IMT measurements were significantly higher in MetS group had than both non-MetS and control groups. Also, EATT was significantly increased in patients with MetS compared to control group. Among MetS obese group, EATT was positively correlated with body mass index-standard deviation score, waist circumference, fasting glucose, fasting insulin, insulin resistance, triglyceride levels, left ventricular thickness, left ventricular mass index and myocardial performance index. EATT was found to be the only predictor of carotid IMT.

Conclusions: EATT is closely related to carotid IMT and early cardiac dysfunction in obese adolescents with MetS.

Keywords: Metabolic Syndrome, Epicardial Adipose Tissue Thickness, Echocardiography
\end{abstract}

\section{Background}

Overweight and obesity in children are increasing in prevalence in both developing and developed countries (1). Abdominal obesity and insulin resistance play an important role in development of metabolic syndrome (MetS). MetS is a combination of disorders that increase the risk of cardiovascular disease and diabetes (2). In contrast to adults; conflicting results were found regarding the relation between obesity and cardiac functions in children. The risk of cardiovascular disease is increased in patients with MetS. Early recognition of premature atherosclerosis is important as subclinical atherosclerosis precedes the clinical manifestations of cardiovascular disease by many years. In patients with MetS, carotid intima-media thickness (IMT) is a marker of subclinical atherosclerosis. Left ventricular hypertrophy, left ventricular diastolic dysfunction, and myocardial dysfunction were reported in MetS patients (3). Previous studies found depressed ventricular functions in MetS patients compared to normal subjects (4). The relationship of EATT with left ventricular mass index and myocardial performance index in obese adolescents with MetS had not been documented (5). EATT, deriving from the same embryological origin as mesenteric and omental fat, is deposited around the heart and coronary vessels. EATT may influence coronary atherosclerosis and myocardial function. EATT has various endocrine and inflammatory functions and produce mediators which can cause endothelial dysfunction. EATT is related to insulin resistance and dyslipidemia and leading to a higher risk of MetS and cardiovascular disease (6).

\section{Objectives}

We aimed to evaluate EATT and carotid IMT of obese children and to study the relationship of EATT with carotid IMT

Copyright (C) 2016, Growth \& Development Research Center. This is an open-access article distributed under the terms of the Creative Commons Attribution-NonCommercial 4.0 International License (http://creativecommons.org/licenses/by-nc/4.0/) which permits copy and redistribute the material just in noncommercial usages, provided the original work is properly cited. 
and other echocardiographic findings as well as clinical parameters of the metabolic syndrome in obese children.

\section{Patients and Methods}

This study was conducted on 60 obese children and adolescent (simple obesity) their ages ranged from (8-16 years) enrolled from pediatric outpatient clinic, Al Hada and Taif Military Hospitals, Saudia Arabia between February 2013 to February 2014.

According to presence or absence of MetS, they were divided into two groups, 22 (36.6\%) were found to show the criteria for MetS diagnosis (MetS group) and 38 (63.4\%) constituted non- MetS group. 25 apparently healthy children of matched age and sex served as controls. All children included in the study gave written consent from participant parents. The study protocol conforms to the ethical guidelines of the 1975 Declaration of Helsinki.

\subsection{Exclusion Criteria}

1) Smoking; 2) Any chronic medication; 3) Family history of premature vascular disease; 4) Any endocrinal disorder; 5) Patients with underlying etiology (secondary obesity).

\subsection{All Patients and Controls Were Subjected to}

1) History taking; 2) Clinical examination and anthropometry: All anthropometric measurements were taken; body height and weight were measured in light clothes by a portable stadiometer. Body mass index was calculated as weight divided by the square of the height $\left(\mathrm{kg} / \mathrm{m}^{2}\right)$. In children, body mass index $>95$ th percentile is considered obese, so we used body mass index $>30$ as obese, and body mass index $<25$ as non-obese control level (7). Waist circumference was measured at the high point of the iliac crest to the nearest $0.1 \mathrm{~cm}$ at the end of normal expiration with a non-stretch measure tape (8). Blood pressure was measured using a mercury sphygmomanometer with different cuff sizes. All measures were evaluated according to appropriate centiles. MetS was defined according to the criteria of International Diabetes Federation which required three or more of the following parameters: abdominal obesity, hypertension, hyperglycemia, high triglyceride and low high density lipoprotein levels.

\subsection{Laboratory Investigations}

Measurement of fasting glucose by glucose hexokinase method (8). Measurement of serum lipids included serum total cholesterol, low density lipoprotein cholesterol, high density lipoprotein cholesterol and triglyceride levels. They were measured by taking venous blood samples in the morning after overnight fasting (10 - 12 hour). Measures were done using standard enzymatic methods by Boehringer Mannheim $\mathrm{GmbH}$ and a fully automatic analyzer (9). High-sensitivity C-reactive protein was assessed by immune nephelometric assay method using company reagents (10). Fasting serum insulin was measured using the chemiluminescent technique (DPC kit on Immulite 1000). Homeostasis model assessment index was used for calculation of insulin resistance (11).

\subsection{Echocardiographic Examination}

Using 3- and 7-MHz transducers Echocardiographic measures were performed with Vivid3 Expert (Norway). The procedure was done without the need for sedative medication. According to the recommendations of the American Society of Echocardiography, chamber dimensions and wall thicknesses were obtained by 2-dimensionally guided M mode (12). Systolic functions of the left ventricle (ejection fraction and fractional shortening) were evaluated by measuring left ventricular end-systolic and end-diastolic dimensions, interventricular septum systolic and diastolic thicknesses, and left ventricular posterior wall systolic and diastolic thicknesses. Left ventricular mass and relative posterior wall thickness was calculated according to the standard formulae (13). Diastolic functions of the left ventricle were evaluated by measuring peak early diastolic filling velocity $(E)$, peak late diastolic filling velocity (A), E/A ratio, and deceleration time (14). Epicardial adipose tissue was measured as the echo-free space over the pericardial layers using 2-dimensional echocardiography. Whereas the epicardial adipose tissue thickness was measured on the free wall of the right ventricle, perpendicular to the wall from parasternal long and short axis views at end-diastole. The measurement was done for 3 cardiac cycles (15). Using a 7-MHz probe, carotid IMT was measured from the common carotid artery at a point $5 \mathrm{~mm}$ proximal to its bifurcation (16). Using a 3-MHz transducer, Pulsed Doppler and tissue Doppler were performed. Early (E) and atrial (A) transmitral maximal flow velocities were measured by pulsed-wave Doppler. The ratio E/A was calculated. Early (E') and late (A') diastolic peak velocities were measured and we calculated the ratio of early and late diastolic annular velocities. Cardiac time intervals-isovolumic contraction time, isovolumic relaxation time, and systolic ejection time were measured. Tissue Doppler derived by myocardial performance index was calculated according to the formulae: (isovolumic contraction time + isovolemic relaxation time)/systolic ejection time. Also; we measured E' wave acceleration and deceleration times (17).

\section{Results}

Results of our study are shown in the following Tables and Figures. Table 1 show clinical and laboratory data of obese and control groups.

To the presence or absence of MetS, obese adolescents were divided into two groups, 22 (36.6\%) were found to have the diagnosis of Mets.

The studied groups showed no significant differences regarding to age. However, the groups differed significantly in terms of body mass index. 
Systolic and diastolic blood pressure values were significantly higher in obese group with MetS than the nonMetS and the control groups. Total cholesterol, triglyceride, low density lipoprotein cholesterol, fasting glucose, insulin levels, and homeostasis model assessment index of insulin resistance were significantly higher in MetS obese group than the non- MetS obese and the control groups, whereas high density lipoprotein cholesterol levels were significantly lower in the MetS obese group than the non- MetS and control groups. Blood pressure values, body mass index, body mass index-standard deviation score and waist circumference were significant- ly higher in the non-MetS obese group than the control group. Also, total cholesterol, triglyceride, low density lipoprotein cholesterol, fasting glucose and insulin levels were significantly higher in the non-MetS obese group than the control group. High density lipoprotein cholesterol levels were significantly lower in the nonMetS obese group than the control group. Homeostasis model assessment index of insulin resistance values were significantly lower in the control group than both non-MetS and MetS obese groups. Table 2 shows measurements of Echocardiography in obese (MetS-NonMetS) and control groups.

Table 1. Clinical and Laboratory Data of Obese and Control Groups

\begin{tabular}{|c|c|c|c|c|c|c|}
\hline \multirow[t]{2}{*}{ Character } & \multirow{2}{*}{$\begin{array}{l}\text { Control Group } \\
(\mathbf{n}=25)\end{array}$} & \multicolumn{2}{|c|}{ Obese Group } & \multirow[t]{2}{*}{$\mathbf{P 1}^{\mathbf{a}}$} & \multirow[t]{2}{*}{$\mathbf{P} 2^{\mathbf{b}}$} & \multirow[t]{2}{*}{ P3 $^{\mathbf{C}}$} \\
\hline & & MetS $(n=22) 36.6 \%$ & Non MetS $(n=38) 63.4 \%$ & & & \\
\hline Age, $y$ & $12.8 \pm 4.1$ & $13.1 \pm 4$ & $12.9 \pm 3.8$ & .081 & .065 & .067 \\
\hline Body mass index, $\mathrm{kg} / \mathrm{m}^{2}$ & $19.8 \pm 1.5$ & $37.2 \pm 3.7$ & $33.8 \pm 8.9$ & .059 & .068 & .082 \\
\hline Body mass index-standard deviation score & $1.2 \pm .1$ & $2.7 \pm .2$ & $2.3 \pm .3$ & .023 & .078 & .014 \\
\hline Hip circumference, $\mathrm{cm}$ & $9.6 \pm 7.4$ & $122.7 \pm 12.4$ & $114.2 \pm 5.9$ & .038 & .041 & .028 \\
\hline Waist circumference, $\mathrm{cm}$ & $66.2 \pm 5.3$ & $112.6 \pm 3.4$ & $10.9 \pm 9.8$ & .047 & .030 & .042 \\
\hline Systolic BP, mmHg & $110 \pm 8.6$ & $15.2 \pm 8.6$ & $128.3 \pm 15.2$ & .019 & .048 & .026 \\
\hline Diastolic BP, mmHg & $7.4 \pm 4$ & $95 \pm 12.3$ & $82.6 \pm 12$ & .026 & .084 & .037 \\
\hline Fasting glucose, mg/dL & $82.9 \pm 8.8$ & $10.2 \pm 8.4$ & $92.6 \pm 7.8$ & .018 & .035 & .028 \\
\hline Total Cholesterol & $165.2 \pm 34.8$ & $192 \pm 34.8$ & $166.9 \pm 37.8$ & .024 & .078 & .049 \\
\hline Triglyceride, mg/dL & $138.9 \pm 41.2$ & $153.3 \pm 56$ & $115 \pm 48.9$ & .036 & .026 & .029 \\
\hline High density lipoprotein cholesterol, mg/dL & $42.8 \pm 18.4$ & $34.1 \pm 8.9$ & $44.8 \pm 12.6$ & .020 & .071 & .038 \\
\hline low density lipoprotein cholesterol, mg/dL & $78.7 \pm 32.6$ & $129.6 \pm 23.6$ & $115 \pm 18.2$ & .017 & .037 & .043 \\
\hline Highly-sensitive C-reactive protein, mg/L & $1.7 \pm .7$ & $2.8 \pm 1.1$ & $1.9 \pm 1.2$ & .038 & .043 & .040 \\
\hline Fasting insulin, mIU/mL & $1.6 \pm 2.4$ & $27.8 \pm 11.9$ & $17.1 \pm 8.4$ & .031 & .040 & .043 \\
\hline Insulin resistance Homa-IR & $2.3 \pm .4$ & $7.1 \pm 3.5$ & $3.8 \pm 2.8$ & .032 & .025 & .028 \\
\hline
\end{tabular}

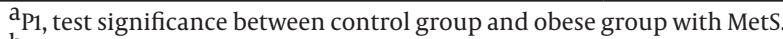

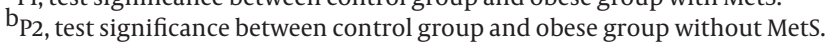

${ }^{\mathrm{C}} \mathrm{P}$, test significance between obese group with MetS and obese group without MetS.

Table 2. Measurements of Echocardiography in Obese (MetS - Non-MetS) and Control Groups

\begin{tabular}{|c|c|c|c|c|c|c|}
\hline \multirow[t]{2}{*}{ Character } & \multirow[t]{2}{*}{ Control Group } & \multicolumn{2}{|c|}{ Obese Group } & \multirow[t]{2}{*}{$\mathbf{P 1}^{\mathbf{a}}$} & \multirow[t]{2}{*}{$\mathbf{P 2} \mathbf{b}^{\mathbf{b}}$} & \multirow[t]{2}{*}{$\mathbf{P 3}^{\mathrm{C}}$} \\
\hline & & MetS & Non-MetS & & & \\
\hline Epicardial adipose tissue thickness, mm & $3.98 \pm 0.93$ & $7.29 \pm 1.58$ & $5.87 \pm 1.77$ & .032 & .019 & .027 \\
\hline Carotid intima-media thickness, mm & $0.48 \pm 0.06$ & $0.87 \pm 0.22$ & $0.74 \pm 0.14$ & .043 & .038 & .046 \\
\hline Left ventricular mass index, $\mathrm{g} / \mathrm{m}^{2}$ & $6.4 \pm 17.8$ & $86.4 \pm 21.3$ & $65.8 \pm 19.1$ & .040 & .036 & .028 \\
\hline Myocardial performance index & $0.41 \pm 0.2$ & $0.53 \pm 0.1$ & $0.42 \pm 0.1$ & .030 & .076 & .087 \\
\hline Ejection time, min & $261.3 \pm 26.4$ & $273.4 \pm 25.8$ & $287.3 \pm 25.7$ & .072 & .091 & .062 \\
\hline Acceleration time, min & $46.8 \pm 6.3$ & $5.4 \pm 7.6$ & $49.8 \pm 6.8$ & .040 & .074 & .082 \\
\hline Deceleration time, min & $77.8 \pm 8.4$ & $68.7 \pm 5.7$ & $75.2 \pm 8.6$ & .020 & .083 & .060 \\
\hline Diastolic early wave peak velocity, cm/s (E') & $17.2 \pm 2.7$ & $16.2 \pm 3.5$ & $16 \pm 2.3$ & .036 & .074 & .058 \\
\hline Diastolic late wave peak velocity, cm/s (A') & $5.8 \pm 1.5$ & $7.5 \pm 2.1$ & $7.8 \pm 1.4$ & .032 & .038 & .064 \\
\hline $\mathbf{E}^{\prime} / \mathbf{A}^{\prime}$ & $2.7 \pm 0.9$ & $2.3 \pm 0.7$ & $2.5 \pm 0.5$ & .030 & .028 & .082 \\
\hline Isovolumic contraction time, min & $58.8 \pm 8.8$ & $72.1 \pm 9.4$ & $66.4 \pm 9$ & .028 & .060 & .029 \\
\hline Isovolumic relaxation time, min & $48.4 \pm 7.8$ & $55.2 \pm 11$ & $5.1 \pm 7.3$ & .030 & .080 & .028 \\
\hline
\end{tabular}

${ }_{\mathrm{P} 1}$, test significance between control group and obese group with MetS.

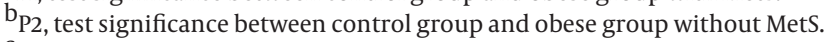

${ }_{\mathrm{C}}^{\mathrm{P}}$, test significance between obese group with MetS and obese group without MetS. 
The MetS obese group had significantly higher EATT, carotid IMT, left ventricular mass index and myocardial performance index values as compared to the both non-MetS and control groups. A statistically significant difference was found between the control and MetS groups regarding the following parameters: acceleration time, deceleration time, diastolic early wave peak velocity (E'), diastolic late wave peak velocity (A'), (E'/A').Also, isovolumic relaxation time, isovolumic contraction values and average myocardial performance index showed statistically sig- nificant difference between the control and MetS groups. The average isovolumic contraction values, isovolumic relaxation time, average myocardial performance index, and average deceleration time were significantly higher in MetS obese group than in non-MetS obese group $(\mathrm{P}<$ 0.05).A significant correlation was found between EATT and carotid IMT among obese patients with MetS.

Table 3 shows the correlation coefficient between (EATT) and clinical, laboratory and echocardiographic parameters in the obese MetS patients and non-MetS.

Table 3. Pearson's Correlation Coefficient Between (EATT) and Clinical, Laboratory and Echocardiographic Parameters in the Obese MetS Patients and Non-Mets

\begin{tabular}{|c|c|c|c|c|}
\hline & \multicolumn{4}{|c|}{ Obese Group } \\
\hline & \multicolumn{2}{|c|}{ With MetS } & \multicolumn{2}{|c|}{ Without MetS } \\
\hline & $\mathbf{R}$ & $\mathbf{P}$ & $\mathbf{R}$ & $\mathbf{P}$ \\
\hline \multicolumn{5}{|l|}{ Vital measurements } \\
\hline Heart rate & .019 & .38 & 0.067 & .26 \\
\hline Systolic blood pressure & .527 & .03 & 0.137 & .12 \\
\hline Diastolic blood pressure & .579 & .005 & 0.512 & .003 \\
\hline \multicolumn{5}{|l|}{ Anthropometry } \\
\hline Body mass index & .621 & .003 & 0.452 & .03 \\
\hline Body mass index-standard deviation score & .697 & .0007 & 0.513 & .0009 \\
\hline Hip circumference & .698 & .0003 & 0.617 & .0007 \\
\hline Waist circumference & .568 & .0005 & 0.474 & .0003 \\
\hline \multicolumn{5}{|l|}{ Laboratory parameters } \\
\hline Fasting glucose, mg/dL & .668 & .0007 & 0.436 & .003 \\
\hline Total Cholesterol & .069 & .87 & 0.062 & .28 \\
\hline Triglyceride, mg/dL & .614 & .0008 & 0.458 & .02 \\
\hline High density lipoprotein cholesterol, mg/dL & .354 & .0008 & -0.013 & .37 \\
\hline low density lipoprotein cholesterol, mg/dL & .102 & .07 & 0.100 & .09 \\
\hline High-sensitivity C-reactive protein, mg/L & .438 & .02 & 0.058 & .16 \\
\hline Fasting insulin, $\mathrm{mIU} / \mathrm{mL}$ & .679 & .0003 & 0.117 & .07 \\
\hline Homeostasis model assessment of insulin resistance & .678 & .0008 & 0.116 & .17 \\
\hline \multicolumn{5}{|l|}{ Left ventricular thickness } \\
\hline Interventricular septum systolic thickness & .143 & .07 & 0.152 & .08 \\
\hline Interventricular septum diastolic thickness & .184 & .08 & 0.176 & .21 \\
\hline Left ventricular posterior wall systolic thickness & .621 & .0006 & 0.1950 & .07 \\
\hline Left ventricular posterior wall diastolic thickness & .688 & .0008 & 0.114 & .06 \\
\hline Left ventricular posterior wall thickness & .448 & .09 & 0.162 & .14 \\
\hline Left ventricular mass index & .747 & .001 & 0.171 & .08 \\
\hline \multicolumn{5}{|l|}{ Left ventricular systolic function } \\
\hline Ejection fraction & .512 & .02 & 0.033 & .07 \\
\hline Fractional shortening & .562 & .04 & 0.728 & .0008 \\
\hline \multicolumn{5}{|l|}{ Left ventricular diastolic function } \\
\hline Diastolic early wave peak velocity, cm/s (E') & .043 & .17 & 0.043 & .35 \\
\hline Diastolic late wave peak velocity cm/s (A') & .038 & .19 & 0.017 & .60 \\
\hline $\mathrm{E}^{\prime} / \mathrm{A}^{\prime}$ & .560 & .08 & 0.031 & .26 \\
\hline Acceleration time, min & .448 & .03 & 0.149 & .13 \\
\hline Deceleration time, min & .074 & .47 & 0.072 & .30 \\
\hline \multicolumn{5}{|l|}{ Left ventricular systolic and diastolic function } \\
\hline Myocardial performance index (MPI) & .478 & .02 & -0.029 & .17 \\
\hline
\end{tabular}


Table 4. Independent Predictors for (EATT) by Multivariate Regression Analysis in MetS) Obese Patients

\begin{tabular}{lcc}
\hline Variables & $\begin{array}{c}\text { Regression } \\
\text { Coefficient }\end{array}$ \\
\hline Systolic blood pressure & .03 & .082 \\
Diastolic blood pressure & .08 & .068 \\
$\begin{array}{l}\text { Body mass index-standard deviation } \\
\text { score }\end{array}$ & .05 & .060 \\
Waist circumference & .02 & .080 \\
Fasting glucose, mg/dL & .26 & .075 \\
Triglyceride, mg/dL & .17 & .064 \\
Fasting insulin, mIU/mL & .19 & .080 \\
Homeostasis model assessment of & .18 & .076 \\
insulin resistance & & \\
Carotid IMT & .62 & .0006 \\
$\begin{array}{l}\text { Left ventricular posterior wall systolic } \\
\text { thickness }\end{array}$ & .06 & .082 \\
$\begin{array}{l}\text { Left ventricular posterior wall diastolic } \\
\text { thickness }\end{array}$ & .04 & .058 \\
Left ventricular mass index & .14 & .070 \\
Myocardial performance index & .10 & .062 \\
\hline
\end{tabular}

Abbreviation: IMT, intima media thickness.

Figure 1. Echcocardiographic Epicardial Adipose Tissue Thickness

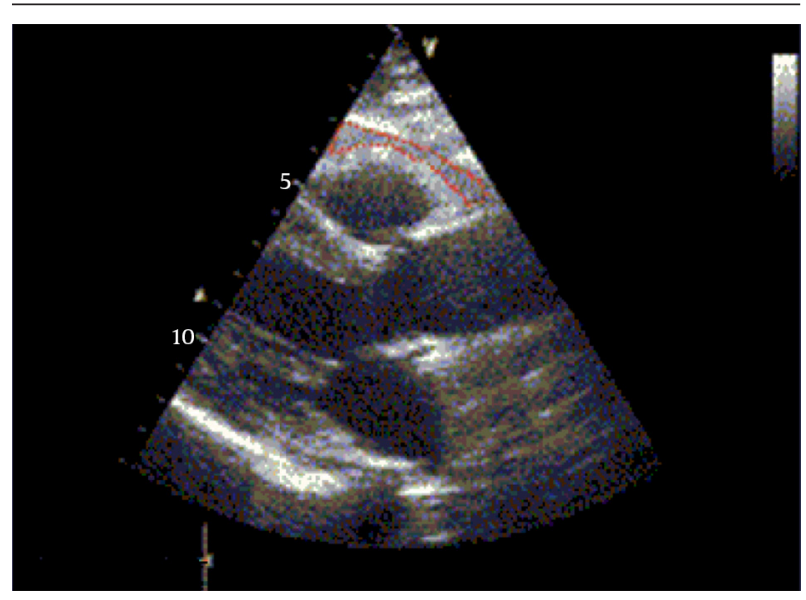

Whit in red dashed shape is identified as the echo free space between the outer wall of the myocardium and the visceral layer of the pericardium in the parasternal long axis view.

EATT was positively correlated with body mass indexstandard deviation score, waist circumference, fasting glucose, fasting insulin, insulin resistance, triglyceride levels, left ventricular thickness, left ventricular mass index and myocardial performance index.

Table 4 shows the multivariate regression model analysis, demonstrated that the only independent predictor of carotid IMT among obese patients with MetS is EATT ( $\beta$ coefficient $=0.62, \mathrm{P}=0.0006$ ) .

Figure 1 shows measurements of echocardiographic epicardial adipose tissue thickness.

Figure 2 shows measurements of the intima-media thickness in the common carotid artery.
Figure 2. Measurements of the Intima-Media Thickness in the Common Carotid Artery Using 7-MHz Linear Probe

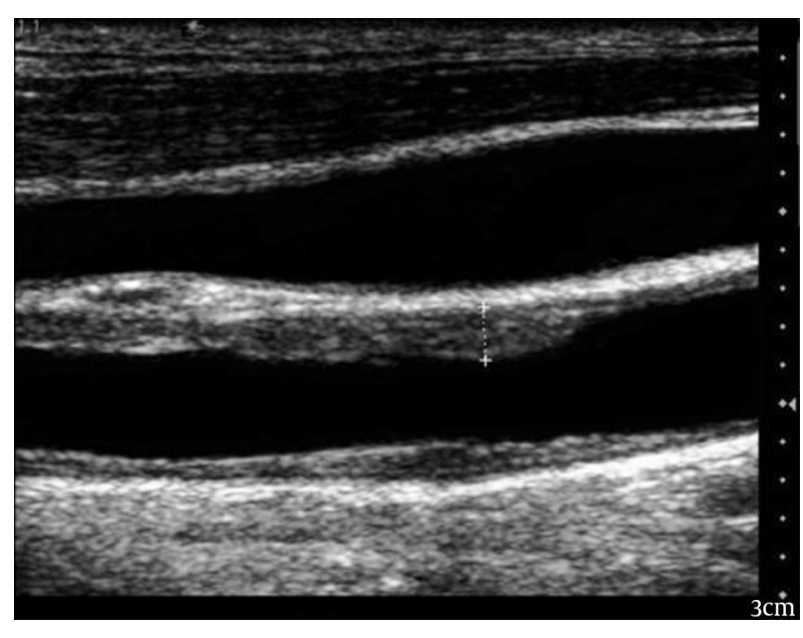

The gray scale ultrasound image shows the cursors placed perpendicular to the long axis of the common carotid artery to include only the intima and media in the thickness measurements.

\section{Discussion}

With the rise in childhood obesity, the related cardiovascular disease in children is becoming more prevalent. Childhood obesity predisposes to an increased risk of morbidity and mortality related to cardiovascular diseases in later life. It has been demonstrated that children may exhibit early signs of cardiovascular dysfunction as a result of their excess adiposity (18). EATT was significantly correlated with anthropometric measures as body mass index and waist circumference in obese adolescents with MetS. We found a high correlation between EATT and body mass index-standard deviation score. This was in agreement of Abaci et al. (2009), Boyraz et al. (2013), and Eren et al. (2014) who reported similar results (19-21). The body mass index was used as a tool to identify individuals at risk of future cardiovascular disease and diabetes. Body mass reflects fat mass and lean body mass, but it does not discriminate the distribution of fat (22). As a risk factor for cardiovascular and metabolic diseases, it was suggested that abdominal adiposity is more important than general adiposity (23). Abdominal fat contributes to the risk of these diseases but the mechanisms are not fully understood.

Among metabolic elements of abdominal fat, is the visceral adipose tissue which probably plays a vital role in this process (24). In our study, epicardial fat showed a positive correlation with waist circumference in obese adolescents. This is in agreement with other authors (3, 19, 20) who found that waist circumference is a good predictor of visceral fat mass and the strongest determinant of EATT.Our data suggests that EATT can be used as indirect estimate of visceral fat. In our study, there was a significant correlation between EATT and the following 
laboratory measures; fasting insulin, insulin resistance, triglyceride, and high sensitivity C-reactive protein. Our findings are in agreement of Akyol et al. 2013 (25). In the present study, there is positive correlation between EATT and homeostasis model assessment index of insulin resistance. In fact, this is an expected finding in the patient group with MetS as epicardial adipose tissue is a component of abdominal fat and its increased amount in MetS patients contributes to increase insulin resistance. There are also some studies that have established a significant correlation between EATT and insulin resistance supporting the present study $(26,27)$. EATT plays a role in the development of inflammation, which triggers the pathogenetic mechanisms of diabetes mellitus, cardiovascular disease, and MetS. In the previous study by Mazurek et al. the expression of inflammatory mediators in the epicardial adipose tissue was greater than that released from subcutaneous adipose tissue in the patients with documented coronary artery disease (28). In the present study, the level of high sensitivity C-reactive protein, the indicator of a low-grade chronic inflammation, was higher compared to the control group. Additionally, a positive correlation was established between EATT, which was higher in the MetS patients, and high sensitivity C-reactive protein which is considered to be another important finding. In other words, visceral adipose tissue, such as EATT, may directly contribute to the development of MetS due to its local and systemic pro-inflammatory effect. In our study; EATT and carotid IMT measurements were increased in obese adolescents with MetS. Also, they have greater left ventricular mass index and myocardial performance index measurements in comparison to control and nonMetS obese groups. In MetS obese patients, there were significant correlations between EATT and hypertension, echocardiographic parameters such as left ventricular thickness, left ventricular mass index, myocardial performance index and carotid IMT. Similar findings were reported by Ozdmir et al. (2010), Akyol et al. (2013), Boyraz et al. (2013), and Eren et al. (2014) (3, 20, 21, 25). Until now, magnetic resonance imaging has been accepted as the gold standard for measuring EATT. however, its coast and radiation risk limit its use as a screening tool. The development of echocardiographic measurement of EATT was first reported by lacobellis et al. (2003). Their study suggests that echocardiographic EATT is a simple and an easy measure in clinical practice (15). In our study, we showed that echocardiographic measurements of EATT significantly correlated with left ventricular mass index and systolic and diastolic function in obese adolescent with MetS. A recent meta-analysis demonstrated significantly higher echocardiographic EAT thickness in patients with MS (29) .EAT thickness is also related to obstructive coronary artery disease, cardiac ischemia, adverse cardiac events and subclinical coronary artery disease (30, 31). Other studies have also shown associations of EATT with diastolic function abnormalities and also left ventricular structural and functional changes $(32,33)$. Myocardial performance index is a new measure in the setting of echocardiography. It can be used to evaluate both systolic and diastolic functions as it correlates well with invasive measurements (34). In our study population, the correlates of EATT were body mass index, waist circumference and hip circumference, fasting glucose and insulin levels, homeostasis model assessment index of insulin resistance, high density lipoprotein, triglyceride levels, high sensitivity C-reactive protein, left ventricular thickness, left ventricular mass index, myocardial performance index and carotid IMT.In multivariate logistic regression analysis, EATT was the only independent variable that was significantly associated with carotid IMT. EATT has been suggested as a new cardiometabolic risk factor as it reflects visceral fat tissue and obesity. Similar results were reported by Akyol et al. (25). Carotid IMT is a noninvasive, feasible, reliable and inexpensive marker of subclinical atherosclerosis. Carotid IMT was related to cardiovascular risk factors and could predict the possibility of future cardio-cerebrovascular disease (35). In a recent study, carotid IMT was significantly increased in the obese group compared with the lean group. In addition, a statistically significant correlation was found between EATT and carotid IMT measurements. These findings suggested that EATT is a more reliable marker of development of subclinical atherosclerosis than the other parameters in obese patients (20). EATT leads to endothelial dysfunction, a key event in the development of atherosclerosis predating clinically obvious vascular disease (36). This may contribute to the initiation, progression and acceleration of coronary artery disease in patients with MetS. For this reason, EATT may be used as additional and easy diagnostic tools for the presence of endothelial dysfunction and the necessity for follow-up for possible future overt coronary artery disease. In a recent study, Iacobellis et al. demonstrated that EATT was found to be a good predictor of steatosis of non-cardiac organs such as the liver (37). EATT is reported to be a marker for the presence and severity of coronary artery disease in recent studies (38). Our results support these studies and suggest the possible association of EATT with subclinical atherosclerosis. In conclusion, we have observed that EATT, carotid IMT, left ventricular mass index and myocardial performance index values were significantly higher in obese adolescents especially with MetS. EATT had a close link with carotid IMT and early cardiac dysfunction in obese adolescents with MetS. Assessment of EATT in routine echocardiography might be a feasible and reliable method for the evaluation of obesity and its related cardiovascular risks during childhood. EATT might be a surrogate marker of subclinical atherosclerosis.

\section{Acknowledgments}

We express our sincere thanks and gratitude to Echo technition and nurses of pediatric department of Al Hada and Taif Military hospitals for their valuable collaboration. 


\section{Footnote}

Authors' Contribution:Study conception and design: Hatem Hamed Elshorbagy; acquisition of data: ElSaeed R. Fouda, Naglaa M .kamal, Mohammed M. Bassiouny and Waleed M. Fathi; analysis and interpretation of data: Hatem Hamed Elshorbagy, ElSaeed R. Fouda and Waleed M. Fathi; drafting of manuscript: Naglaa M. kamal, Mohammed M. Bassiouny and Waleed M.Fathi; critical revision: Hatem Hamed Elshorbagy and ElSaeed R. Fouda.

\section{References}

1. Van Putte-Katier N, Rooman RP, Haas L, Verhulst SL, Desager $\mathrm{KN}$, Ramet J, et al. Early cardiac abnormalities in obese children: importance of obesity per se versus associated cardiovascular risk factors. Pediatr Res. 2008;64(2):205-9. doi: 10.1203/ PDR.ob013e318176182b. [PubMed:18391840]

2. Grundy SM, Brewer HB, Cleeman JI, Smith SC, Lenfant C, American Heart A, et al. Definition of metabolic syndrome: Report of the National Heart, Lung, and Blood Institute/American Heart Association conference on scientific issues related to definition. Circulation. 2004;109(3):433-8. doi: 10.1161/01.CIR.0000111245.75752. C6. [PubMed:14744958]

3. Ozdemir O, Hizli S, Abaci A, Agladioglu K, Aksoy S. Echocardiographic measurement of epicardial adipose tissue in obese children. Pediatr Cardiol. 2010;31(6):853-60. doi: 10.1007/s00246-0109720-y. [PubMed: 20461364]

4. Voulgari C, Moyssakis I, Papazafiropoulou A, Perrea D, Kyriaki $\mathrm{D}$, Katsilambros N, et al. The impact of metabolic syndrome on left ventricular myocardial performance. Diabetes Metab Res Rev. 2010;26(2):121-7. doi: 10.1002/dmrr.1063. [PubMed: 20131336]

5. Gastaldelli A, Basta G. Ectopic fat and cardiovascular disease: what is the link? Nutr Metab Cardiovasc Dis. 2010;20(7):481-90. doi:10.1016/j.numecd.2010.05.005. [PubMed:20659791]

6. Sacks HS, Fain JN. Human epicardial adipose tissue: a review. Am Heart J. 2007;153(6):907-17. doi: 10.1016/j.ahj.2007.03.019. [PubMed:17540190]

7. Cole TJ, Bellizzi MC, Flegal KM, Dietz WH. Establishing a standard definition for child overweight and obesity worldwide: international survey. BMJ. 2000;320(7244):1240-3. [PubMed:10797032]

8. Shea S, Aymong E, Zybert P, Shamoon H, Tracy RP, Deckelbaum RJ, et al. Obesity, fasting plasma insulin, and C-reactive protein levels in healthy children. Obes Res. 2003;11(1):95-103. doi: 10.1038| oby.2003.15. [PubMed:12529491]

9. Vikram NK, Misra A, Dwivedi M, Sharma R, Pandey RM, Luthra $\mathrm{K}$, et al. Correlations of C-reactive protein levels with anthropometric profile, percentage of body fat and lipids in healthy adolescents and young adults in urban North India. Atherosclerosis. 2003;168(2):305-13. [PubMed:12801614]

10. Roberts WL, Moulton L, Law TC, Farrow G, Cooper-Anderson M, Savory J, et al. Evaluation of nine automated high-sensitivity C-reactive protein methods: implications for clinical and epidemiological applications. Part 2. Clin Chem. 2001;47(3):418-25. [PubMed: 11238291]

11. Keskin M, Kurtoglu S, Kendirci M, Atabek ME, Yazici C. Homeostasis model assessment is more reliable than the fasting glucose/ insulin ratio and quantitative insulin sensitivity check index for assessing insulin resistance among obese children and adolescents. Pediatrics. 2005;115(4):e500-3. doi: 10.1542/peds.2004-1921. [PubMed:15741351]

12. Sahn DJ, DeMaria A, Kisslo J, Weyman A. Recommendations regarding quantitation in M-mode echocardiography: results of a survey of echocardiographic measurements. Circulation. 1978;58(6):1072-83. [PubMed: 709763]

13. Devereux RB, Lutas EM, Casale PN, Kligfield P, Eisenberg RR, Hammond IW, et al. Standardization of M-mode echocardiographic left ventricular anatomic measurements. J Am Coll Cardiol. 1984;4(6):1222-30. [PubMed: 6238987]

14. Spirito P, Maron BJ, Bonow RO. Noninvasive assessment of left ventricular diastolic function: comparative analysis of Doppler echocardiographic and radionuclide angiographic techniques. $J$ Am Coll Cardiol.1986;7(3):518-26. [PubMed:3950231]

15. Iacobellis G, Ribaudo MC, Assael F, Vecci E, Tiberti C, Zappaterreno A, et al. Echocardiographic epicardial adipose tissue is related to anthropometric and clinical parameters of metabolic syndrome: a new indicator of cardiovascular risk. J Clin Endocrinol Metab. 2003;88(11):5163-8. doi: 10.1210/jc.2003-030698. [PubMed: 14602744]

16. Touboul PJ, Hennerici MG, Meairs S, Adams H, Amarenco P, Bornstein $\mathrm{N}$, et al. Mannheim carotid intima-media thickness consensus (2004-2006). An update on behalf of the Advisory Board of the 3rd and 4th Watching the Risk Symposium, 13th and 15th European Stroke Conferences, Mannheim, Germany, 2004, and Brussels, Belgium, 2006. Cerebrovasc Dis. 2007;23(1):75-80. doi: 10.1159/000097034. [PubMed: 17108679]

17. Spirito P, Maron BJ, Bonow RO. Noninvasive assessment of left ventricular diastolic function: Comparative analysis of Doppler echocardiographic and radionuclide angiographic techniques. $J$ Am Coll Cardiol.1986;7(3):518-26. doi:10.1016/s0735-1097(86)804612. [PubMed: 3950231]

18. Cote AT, Harris KC, Panagiotopoulos C, Sandor GG, Devlin AM. Childhood obesity and cardiovascular dysfunction.J Am Coll Cardiol. 2013;62(15):1309-19. doi: 10.1016/j.jacc.2013.07.042. [PubMed: 23954339]

19. Abaci A, Tascilar ME, Saritas T, Yozgat Y, Yesilkaya E, Kilic A, et al. Threshold value of subepicardial adipose tissue to detect insulin resistance in obese children. Int J Obes (Lond). 2009;33(4):440-6. doi:10.1038/ijo.2009.1. [PubMed:19223846]

20. Boyraz M, Pirgon O, Akyol B, Dundar B, Cekmez F, Eren N. Importance of epicardial adipose tissue thickness measurement in obese adolescents, its relationship with carotid intima-media thickness, and echocardiographic findings. Eur Rev Med Pharmacol Sci. 2013;17(24):3309-17. [PubMed: 24379061]

21. Eren E, Koca B, Ture M, Guzel B. Epicardial adiposity in children with obesity and metabolic syndrome. Iran $J$ Pediatr. 2014;24(4):411-7. [PubMed: 25755863]

22. Mason C, Craig CL, Katzmarzyk PT. Influence of central and extremity circumferences on all-cause mortality in men and women. Obesity (Silver Spring). 2008;16(12):2690-5. doi: 10.1038/ oby.2008.438. [PubMed:18927548]

23. Janssen I, Katzmarzyk PT, Ross R. Waist circumference and not body mass index explains obesity-related health risk. Am J Clin Nutr. 2004;79(3):379-84. [PubMed:14985210]

24. DespresJP.Isvisceralobesitythecause of themetabolicsyndrome? Ann Med. 2006;38(1):52-63. doi: 10.1080/07853890500383895. [PubMed:16448989]

25. Akyol B, Boyraz M, Aysoy C. Relationship of epicardial adipose tissue thickness with early indicators of atherosclerosis and cardiac functional changes in obese adolescents with metabolic syndrome. J Clin Res Pediatr Endocrinol. 2013;5(3):156-63. doi:10.4274/ Jcrpe.1064. [PubMed: 24072083]

26. Blachnio-Zabielska AU, Baranowski M, Hirnle T, Zabielski P, Lewczuk A, Dmitruk I, et al. Increased bioactive lipids content in human subcutaneous and epicardial fat tissue correlates with insulin resistance. Lipids. 2012;47(12):1131-41. doi: 10.1007/s11745012-3722-x. [PubMed: 23054552]

27. Fernandez Munoz MI, Basurto Acevedo L, Cordova Perez N, Vazquez Martinez AL, Tepach Gutierrez N, Vega Garcia S, et al. Epicardial adipose tissue is associated with visceral fat, metabolic syndrome, and insulin resistance in menopausal women. Rev Esp Cardiol (Engl Ed). 2014;67(6):436-41. doi: 10.1016/j.rec.2013.10.011. [PubMed: 24863591]

28. Mazurek T, Zhang L, Zalewski A, Mannion JD, Diehl JT, Arafat H, et al. Human epicardial adipose tissue is a source of inflammatory mediators. Circulation. 2003;108(20):2460-6. doi: 10.1161/01. CIR.0000099542.57313.C5. [PubMed:14581396]

29. Pierdomenico SD, Pierdomenico AM, Cuccurullo F, Iacobellis G. Meta-analysis of the relation of echocardiographic epicardial adipose tissue thickness and the metabolic syndrome. Am J Cardiol.2013;111(1):73-8. doi:10.1016/j.amjcard.2012.08.044. [PubMed: 23040591] 
30. Alam MS, Green R, de Kemp R, Beanlands RS, Chow BJ. Epicardial adipose tissue thickness as a predictor of impaired microvascular function in patients with non-obstructive coronary artery disease. J Nucl Cardiol. 2013;20(5):804-12. doi: 10.1007/s12350-0139739-6. [PubMed: 23749262]

31. Tamarappoo B, Dey D, Shmilovich H, Nakazato R, Gransar H, Cheng VY, et al. Increased pericardial fat volume measured from noncontrast CT predicts myocardial ischemia by SPECT. JACC Cardiovasc Imaging. 2010;3(11):1104-12. doi:10.1016/j.jcmg.2010.07.014 [PubMed: 21070997]

32. Cavalcante JL, Tamarappoo BK, Hachamovitch R, Kwon DH, Alraies MC, Halliburton S, et al. Association of epicardial fat, hypertension, subclinical coronary artery disease, and metabolic syndrome with left ventricular diastolic dysfunction. Am JCardiol.2012;110(12):17938. doi:10.1016/j.amjcard.2012.07.045. [PubMed: 22980968]

33. Khawaja T, Greer C, Chokshi A, Chavarria N, Thadani S, Jones M, et al. Epicardial fat volume in patients with left ventricular systolic dysfunction. Am J Cardiol. 2011;108(3):397-401. doi: 10.1016/j.amjcard.2011.03.058. [PubMed: 21565323]

34. Tei C, Ling LH, Hodge DO, Bailey KR, Oh JK, Rodeheffer RJ, et al. New index of combined systolic and diastolic myocardial per- formance: a simple and reproducible measure of cardiac function--a study in normals and dilated cardiomyopathy. J Cardiol. 1995;26(6):357-66. [PubMed: 8558414]

35. Lorenz MW, Markus HS, Bots ML, Rosvall M, Sitzer M. Prediction of clinical cardiovascular events with carotid intima-media thickness: a systematic review and meta-analysis. Circulation. 2007;115(4):459-67. doi: 10.1161/CIRCULATIONAHA.106.628875. [PubMed:17242284]

36. Aydin H, Toprak A, Deyneli O, Yazici D, Tarcin O, Sancak S, et al Epicardial fat tissue thickness correlates with endothelial dysfunction and other cardiovascular risk factors in patients with metabolic syndrome. Metab Syndr Relat Disord. 2010;8(3):229-34. doi:10.1089/met.2009.0080. [PubMed:20156077]

37. Iacobellis G, Barbarini G, Letizia C, Barbaro G. Epicardial fat thickness and nonalcoholic fatty liver disease in obese subjects. Obesity (Silver Spring). 2014;22(2):332-6. doi: 10.1002/oby.20624. [PubMed: 24115757]

38. Alexopoulos N, McLean DS, Janik M, Arepalli CD, Stillman AE, Raggi P. Epicardial adipose tissue and coronary artery plaque characteristics. Atherosclerosis. 2010;210(1):150-4. doi: 10.1016/j. atherosclerosis.2009.11.020. [PubMed: 20031133] 